Supplement of Ocean Sci., 15, 477-488, 2019

https://doi.org/10.5194/os-15-477-2019-supplement

(C) Author(s) 2019. This work is distributed under

the Creative Commons Attribution 4.0 License.

(c) (1)

Supplement of

\title{
Estimation of geostrophic current in the Red Sea based on sea level anomalies derived from extended satellite altimetry data
}

\author{
Ahmed Mohammed Taqi et al. \\ Correspondence to: Ahmed Mohammed Taqi (ataqi@stu.kau.edu.sa)
}

The copyright of individual parts of the supplement might differ from the CC BY 4.0 License. 

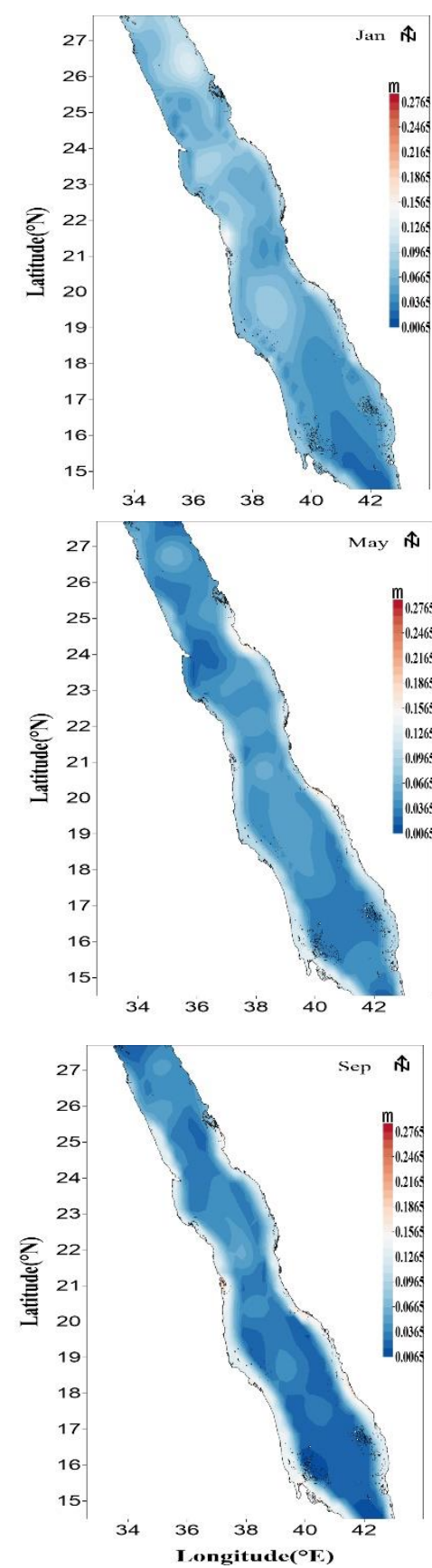
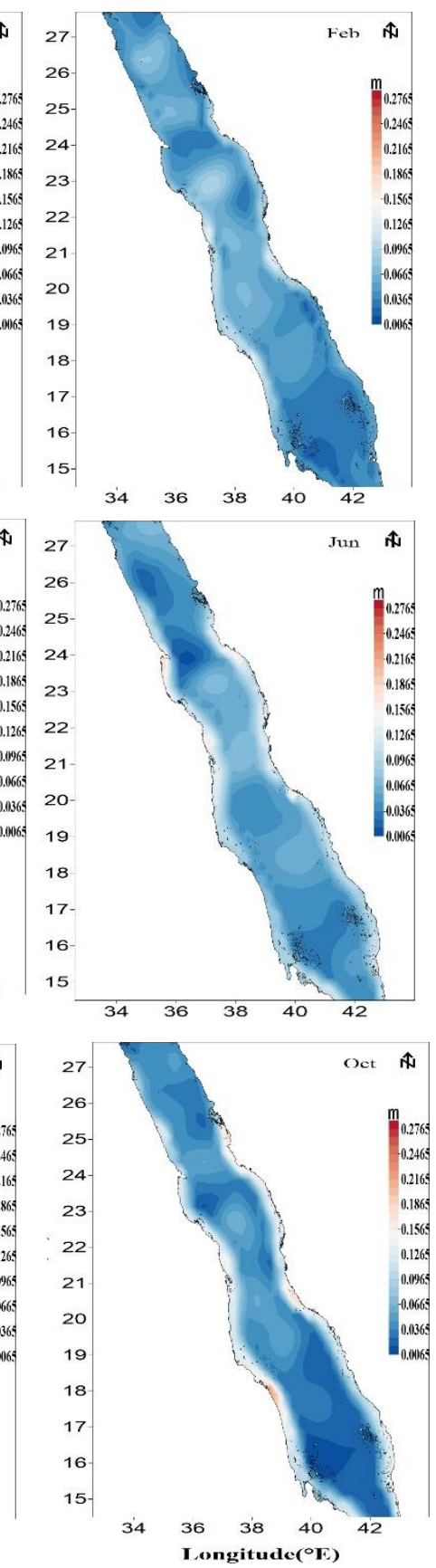
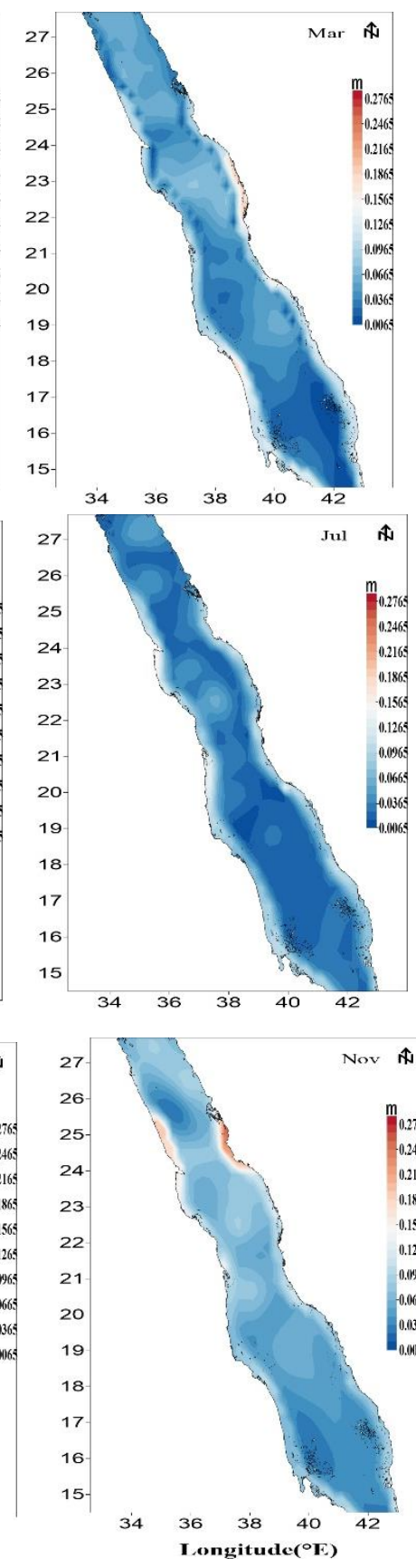
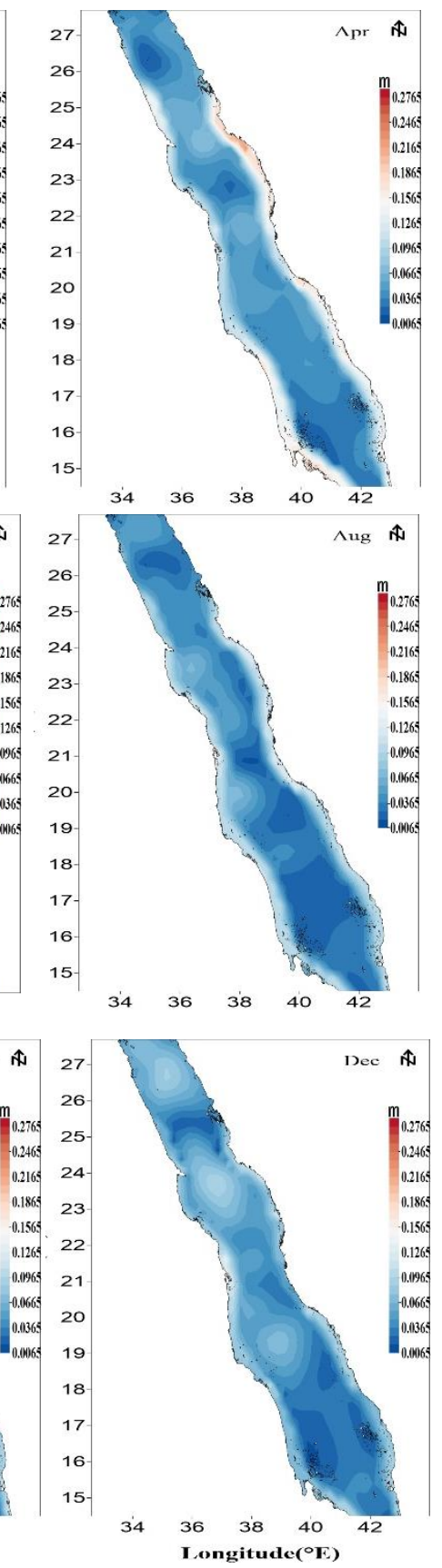

Figure S1 Standard deviation of each month from different year from the monthly climatology

Table S1 Minimum, maximum and mean standard deviation of each month from different year from the monthly climatology

\begin{tabular}{|l|l|l|l|l|l|l|l|l|l|l|l|l|}
\hline & jan & feb & mar & apr & may & jun & jul & aug & sep & oct & Nov & Dec \\
\hline min & 0.016 & 0.011 & 0.008 & 0.016 & 0.014 & 0.011 & 0.010 & 0.013 & 0.013 & 0.007 & 0.018 & 0.009 \\
\hline max & 0.160 & 0.137 & 0.192 & 0.232 & 0.169 & 0.178 & 0.149 & 0.131 & 0.186 & 0.209 & 0.241 & 0.135 \\
\hline mean & 0.064 & 0.050 & 0.054 & 0.067 & 0.056 & 0.061 & 0.044 & 0.050 & 0.056 & 0.057 & 0.070 & 0.052 \\
\hline
\end{tabular}

